\title{
Normal saline as resuscitation fluid in critically ill patients: not dead yet!
}

CrossMark

\author{
Patrick M. Honore ${ }^{*}$, Rita Jacobs and Herbert D. Spapen
}

In this issue of Annals of Intensive Care, Van Regenmortel et al. report a significant association between hyperchloremia present on the first day of intensive care unit (ICU) admission and ICU and hospital mortality in a large cohort of ICU patients. However, chloride levels were significantly higher and mortality was lower in cardiac surgery patients than in the entire cohort [1].

Hyperchloremia is increasingly stigmatized to negatively influence kidney function and mortality in ICU patients. Paradoxically, normal saline ( $\mathrm{NaCl} 0.9 \%$; NS) the worldwide number one solution for patient resuscitation purposes-contains supraphysiologic concentrations of chloride and, when amply infused, inevitably causes hyperchloremic metabolic acidosis (HMA) [2]. Animal models typically highlight the adverse and unwarranted effects of NS-induced HMA such as greater hemodynamic instability, altered microcirculation, and enhanced or persistent inflammation [3, 4]. Growing aversion for NS produced a surge of studies comparing NS with different "balanced" crystalloid solutions. The latter (i.e., Ringer's solution, Hartmann's solution, and PlasmaLyte $^{\circledR}$ ) more closely resemble the electrolyte component of plasma but, most importantly, contain much less chloride than NS (109, 111, and $98 \mathrm{mmol} / \mathrm{L}$, respectively).

Basically, the case against NS is entirely built on its disruptive effect on acid-base homeostasis. Among the different viewpoints on acid-base equilibrium, the Stewart-Figge approach explains NS-induced acidosis by an increase in chloride anion concentration. According to this method, the apparent strong ion difference (SIDa) is an independent variable that is unaltered by unidirectional sodium and chloride changes and thus a more appropriate detector of fluid-related HMA [5]. As the SIDa of NS equals zero, infusion of NS will decrease plasma SIDa and contribute to metabolic acidosis. The

*Correspondence: Patrick.Honore@az.vub.ac.be ICU Department, Universitair Ziekenhuis Brussel, Vrije Universiteit Brussel, 101, Laarbeeklaan, 1090 Brussels, Belgium observation by Van Regenmortel et al. that a decreased SIDa (excluding lactate) did not have an impact on mortality thus argues against a deleterious infusion-related role of chloride in se [1].

Several arguments strongly plead against a too precipitous verdict on NS. A randomized, controlled, double-blind crossover study comparing the effects of a $2 \mathrm{~L}$ infusion of $0.9 \%$ NS versus Plasma-Lyte ${ }^{\circledR}$ in healthy volunteers demonstrated significant reductions in mean renal artery flow velocity $(P=0.045)$ and renal cortical tissue perfusion $(P=0.008)$ from baseline after NS. However, there was no evidence of relevant acute kidney injury (AKI) as shown by similar concentrations of urinary neutrophil gelatinase-associated lipocalin in both infusion groups [6]. A meta-analysis assessing high- versus low-chloride infusion in 6253 peri-operative and critically ill patients found a significant but weak association between high-chloride content fluids and a higher incidence of AKI. Excluding the most heavy-weighted studies from this analysis, however, rendered the AKI end point non-statistically significant [7]. The subsequently published 0.9\% Saline versus Plasma-Lyte ${ }^{\circledR}$ for Intensive Care Unit Fluid Therapy trial found no difference in incidence of AKI, renal replacement therapy and mortality among patients receiving similar volumes of NS or buffered crystalloid [8]. Moreover, a very recent cluster-randomized crossover study comparing the administration of similar volumes of NS and balanced crystalloids in nearly 1000 patients showed no difference in a composite "major kidney-related adverse events" end point including death, dialysis, and persistent renal dysfunction [9]. Finally, theoretically beneficial effects of NS-induced acidosis such as enhanced tissue oxygen extraction and better protection against hypoxemia have insufficiently been investigated [10].

An inherent but important limitation clouding the retrospective data of Van Regenmortel et al. is the inability to correctly determine the fluid type and volume before ICU admission. Indeed, irrespective of the type 
of admission (medical, surgical, or trauma) and after adjustment for important confounders (illness severity and comorbidities), the need to acutely administer a high volume of fluid or a positive fluid balance over time is independently and reproducibly associated with more ICU complications (including AKI $[11,12])$ and higher mortality [13], especially in patients with underlying kidney or heart disease [14]. In addition, many questions remain unsolved. Are some patient subgroups more chloride-vulnerable? Is a "dose" limitation of NS (e.g., not exceeding $20-30 \mathrm{~mL} / \mathrm{kg}$ ) advised? Are pre-resuscitation chloride concentrations important? Does hyperchloremia only matter when associated with SIDa changes or a particular degree of acidemia? Are all balanced crystalloids equivalent with regard to relevant clinical outcome parameters?

The study of Van Regenmortel et al. indirectly underscores growing equipoise in the expert medical community regarding the presumed harmful effects of NS compared with balanced crystalloids. Future studies, such as the ongoing multicenter randomized PlasmaLyte ${ }^{\circledR}$ versus Saline (PLUS) trial, should hopefully definitively unravel the crystalloid conundrum ate.

\section{Abbreviations}

ICU: intensive care unit; NS: normal saline; HMA: hyperchloremic metabolic acidosis; SIDa: apparent strong ion difference; AKI: acute kidney injury.

\section{Authors' contributions}

PMH and HDS designed the paper. PMH, RJ and HDS participated in drafting and approved the final version.

\section{Competing interests}

The authors declare that they have no competing interests.

Received: 22 November 2016 Accepted: 15 December 2016 Published online: 28 December 2016
References

1. Van Regenmortel N, Verbrugghe W, Van den Wyngaert T, Jorens PG. Impact of chloride and strong ion difference on ICU and hospital mortality in a mixed intensive care population. Ann Intensive Care. 2016;6:91.

2. Lira A, Pinsky MR. Choices in fluid type and volume during resuscitation: impact on patient outcomes. Ann Intensive Care. 2014;4(4):38.

3. Kellum JA, Song M, Venkataraman R. Effects of hyperchloremic acidosis on arterial pressure and circulating inflammatory molecules in experimental sepsis. Chest. 2004;125:243-8.

4. Orbegozo D, Su F, Santacruz C, He X, Hosokawa K, Creteur J, et al. Effects of different crystalloid solutions on hemodynamics, peripheral perfusion, and the microcirculation in experimental abdominal sepsis. Anesthesiology. 2016;125:744-54

5. Kishen R, Honoré PM, Jacobs R, Joannes-Boyau O, De Waele E, De Regt $J$, et al. Facing acid-base disorders in the third millennium - the Stewart approach revisited. Int J Nephrol Renovasc Dis. 2014;7:209-17.

6. Chowdhury AH, Cox EF, Francis ST, Lobo DN. A randomized, controlled, double-blind crossover study on the effects of $2-L$ infusions of $0.9 \%$ saline and plasma-lyte ${ }^{\circledR} 148$ on renal blood flow velocity and renal cortical tissue perfusion in healthy volunteers. Ann Surg. 2012;256:18-24.

7. Krajewski ML, Raghunathan K, Paluszkiewicz SM, Schermer CR. Shaw ADMeta-analysis of high- versus low-chloride content in perioperative and critical care fluid resuscitation. Br J Surg. 2015;102:24-36.

8. Young P, Bailey M, Beasley R, Henderson S, Mackle D, McArthur C, et al. Effect of a buffered crystalloid solution vs saline on acute kidney injury among patients in the intensive care unit: the SPLIT randomized clinical trial. JAMA. 2015;314:1701-10.

9. Semler MW, Wanderer JP, Ehrenfeld JM, Stollings JL, SelfWH, Siew ED, Wang L, Byrne DW, Shaw AD, Bernard GR, Rice TW, SALT Investigators and the Pragmatic Critical Care Research Group. Balanced Crystalloids versus Saline in the Intensive Care Unit: The SALT Randomized Trial. Am J Respir Crit Care Med. 2016. doi:10.1164/rccm.201607-13450C.

10. Ince C, Groeneveld AB. The case for $0.9 \% \mathrm{NaCl}$ : is the undefendable, defensible? Kidney Int. 2014;86:1087-95.

11. Honore PM, Jacobs R, Hendrickx I, Bagshaw SM, Joannes-Boyau O, Boer W, et al. Prevention and treatment of sepsis-induced acute kidney injury: an update. Ann Intensive Care. 2015;5:51.

12. Vinsonneau C, Allain-Launay E, Blayau C, Darmon M, Ducheyron D, Gaillot $\mathrm{T}$, Honore PM, et al. Renal replacement therapy in adult and pediatric intensive care: recommendations by an expert panel from the French Intensive Care Society (SRLF) with the French Society of Anesthesia Intensive Care (SFAR) French Group for Pediatric Intensive Care Emergencies (GFRUP) the French Dialysis Society (SFD). Ann Intensive Care. 2015;5(1):58.

13. Marik PE. latrogenic salt water drowning and the hazards of a high central venous pressure. Ann Intensive Care. 2014;4:21.

14. Lee J, de Louw E, Niemi M, Nelson R, Mark RG, Celi LA, et al. Association between fluid balance and survival in critically ill patients. J Intern Med. 2015;277:468-77.

\section{Submit your manuscript to a SpringerOpen ${ }^{\circ}$ journal and benefit from:}

- Convenient online submission

- Rigorous peer review

- Immediate publication on acceptance

- Open access: articles freely available online

- High visibility within the field

- Retaining the copyright to your article

Submit your next manuscript at springeropen.com 